\title{
The Impact of Patient's Pain and Fatigue on the Discharge Decision After Laparoscopic Surgery for Colorectal Cancer
}

\author{
Won Beom Jung \\ Department of Surgery, Inje University Haeundae Paik Hospital, Inje University College of Medicine, Busan, Korea
}

See Articles on Page 209-215

In Korea, from 2013 to 2015, 57,258 patients underwent open or laparoscopic resections for colorectal cancer (CRC), and the rates of laparoscopic surgery were $65.0 \%, 69.2 \%$, and $72.5 \%$ in 2013 , 2014, and 2015 respectively [1]. Numerous randomized controlled trials have revealed that laparoscopic colorectal surgery has the following advantages over conventional open surgery: less postoperative pain, faster recovery, shorter hospital stay, and earlier return to social activity [2-4]. Therefore, the length of hospital stay for patients who underwent laparoscopic surgery for CRC has decreased compared to that in the past. Moreover, recent guidelines and protocols for perioperative care in elective colorectal surgery, including the clinical pathway and the enhanced recovery after surgery pathway, can lead to faster recovery and faster return to society and can decrease the length of hospital stay [5-7]. However, a concern exists that these guidelines and minimally invasive surgery may result in excessive standardization of hospital stay. Concerning the length of hospital stay, these authors wondered whether other factors, including the patient's education, counseling, the patient's socioeconomic status, and the subjective symptoms of the patients, influenced the decision for discharge [8]. This study aimed to estimate a patient's expectations for discharge after surgery through a questionnaire and to investigate subjective factors that might affect patient satisfaction and the

Correspondence to: Won Beom Jung, M.D.

Department of Surgery, Inje University Haeundae Paik Hospital, Inje University College of Medicine, 875 Haeun-daero, Haeundae-gu, Busan 48108, Korea

Tel: +82-51-797-0266, Fax: +82-51-797-0276

E-mail: lumbermi@gmail.com

ORCID code: https://orcid.org/0000-0001-5427-5964

(C) 2019 The Korean Society of Coloproctology

This is an open-access article distributed under the terms of the Creative Commons Attribution NonCommercial License (http://creativecommons.org/licenses/by-nc/4.0) which permits unrestricted noncommercial use, distribution, and reproduction in any medium, provided the original work is properly cited. discharge decision. The questionnaire consisted of 3 parts. Parts 1 and 2 were given to patients before surgery. Part 1 addressed the patient's demographics, and part 2 addressed the patient's expectations for discharge, such as the amount of food, number of bowel movements until discharge, degree of pain, degree of activity, and self-efficacy. Part 3 addressed the degree of subjective discomfort the patients were experiencing at the time the discharge decision was made.

A total of 91 patients provided consent and were included in the study. According to the results of part 2, the patients thought that the level of activity $(n=35)$, amount of food $(n=24)$, and number of bowel movements $(n=19)$ were more important factors for the discharge decision than the degree of pain $(n=10)$, ability to pay $(n=1)$, and presence of caregivers $(n=2)$. The patients were classified into group A $(n=74)$ who complied with the medical professional's decision on discharge and group $B(n=17)$ who refused discharge against the medical professional's decision. The patients in group B were more likely to have subjective pain, fatigue, and inactivity than those in group A. No significant differences were found between the 2 groups in terms of satisfaction with diet, subjective gastrointestinal symptoms, and subjective daily living activities. This study showed that subjective pain and fatigue were significantly related to the refusal to comply with the discharge decision.

Few comparative studies about the association of hospital stay with subjective symptoms, excluding objective signs and data, have been published [9]. This study focused not only on the subjective symptoms of pain and fatigue but also on education, counseling, and compliance with the physician's decision. A prospective survey, including questionnaires and education materials, such as diagrams of treatment plans and timetables, may reduce the gap between patient's expectation for discharge and the physician's decision. Furthermore, these efforts can avoid generalizing discharge decisions and enhance individualization and personalization in postoperative management of patients after laparoscopic colorectal surgery. 


\section{CONFLICT OF INTEREST}

No potential conflicts of interest relevant to this article were reported.

\section{REFERENCES}

1. Park SJ, Lee KY, Lee SH. Laparoscopic surgery for colorectal cancer in Korea: nationwide data from 2008 2013. J Minim Invasive Surg 2015;18:39-43.

2. Jeong SY, Park JW, Nam BH, Kim S, Kang SB, Lim SB, et al. Open versus laparoscopic surgery for mid-rectal or low-rectal cancer after neoadjuvant chemoradiotherapy (COREAN trial): survival outcomes of an open-label, non-inferiority, randomised controlled trial. Lancet Oncol 2014;15:767-74.

3. van der Pas MH, Haglind E, Cuesta MA, Fürst A, Lacy AM, Hop WC, et al. Laparoscopic versus open surgery for rectal cancer (COLOR II): short-term outcomes of a randomised, phase 3 trial. Lancet Oncol 2013;14:210-8.

4. Clinical Outcomes of Surgical Therapy Study Group, Nelson H,
Sargent DJ, Wieand HS, Fleshman J, Anvari M, et al. A comparison of laparoscopically assisted and open colectomy for colon cancer. N Engl J Med 2004;350:2050-9.

5. Gustafsson UO, Scott MJ, Hubner M, Nygren J, Demartines N, Francis N, et al. Guidelines for perioperative care in elective colorectal surgery: Enhanced Recovery After Surgery (ERAS $\left({ }^{\circledR}\right)$ ) Society Recommendations: 2018. World J Surg 2019;43:659-95.

6. Fearon KC, Ljungqvist O, Von Meyenfeldt M, Revhaug A, Dejong $\mathrm{CH}$, Lassen $\mathrm{K}$, et al. Enhanced recovery after surgery: a consensus review of clinical care for patients undergoing colonic resection. Clin Nutr 2005;24:466-77.

7. Visioni A, Shah R, Gabriel E, Attwood K, Kukar M, Nurkin S. Enhanced recovery after surgery for noncolorectal surgery?: a systematic review and meta-analysis of major abdominal surgery. Ann Surg 2018;267:57-65.

8. Lee G, Lee JS, Kim JH, Hwang DY, Lee YS. Impact of patient's pain and fatigue on decision of discharge after laparoscopic surgery for colorectal cancer. Ann Coloproctol 2019;35:209-15.

9. Kruzik N. Benefits of preoperative education for adult elective surgery patients. AORN J 2009;90:381-7. 